\title{
BMJ Open Ethnic disparities in prevalence and patterns of smoking and nicotine dependence in rural southwest China: a cross-sectional study
}

Xu-Ming Wang, Chao Wu, Allison Rabkin Golden, Cai Le

To cite: Wang X-M, Wu C, Golden AR, et al. Ethnic disparities in prevalence and patterns of smoking and nicotine dependence in rural southwest China: a crosssectional study. BMJ Open 2019;9:e028770. doi:10.1136/ bmjopen-2018-028770

- Prepublication history for this paper is available online. To view these files, please visit the journal online (http://dx.doi. org/10.1136/bmjopen-2018028770).

X-MW and CW contributed equally.

X-MW and CW are first coauthors.

Received 26 December 2018 Revised 01 August 2019 Accepted 03 September 2019

Check for updates

(C) Author(s) (or their employer(s)) 2019. Re-use permitted under CC BY-NC. No commercial re-use. See rights and permissions. Published by BMJ.

School of Public Health, Kunming Medical University in Kunming, Kunming, China

Correspondence to

Dr Cai Le

caile002@hotmail.com

\section{ABSTRACT}

Objectives This study examines ethnic disparities in prevalence and patterns of smoking and nicotine dependence in rural southwest China.

Design This was a cross-sectional design.

Setting This study was conducted in rural Yunnan Province of China.

Participants 7027 consenting individuals aged $\geq 35$ years among Han majority and four ethnic minority groups (Na Xi, Li Shu, Dai and Jing Po) participated in this study. Information about participants' demographic characteristics as well as smoking habits and an assessment of nicotine dependence with the Fagerstrom Test for Nicotine Dependence (FTND) was obtained using a standard questionnaire.

Results Males had significantly higher prevalence of current smoking than females $(64.8 \%$ and $44.4 \%$, $\mathrm{p}<0.01)$. Among current smokers, the prevalence of nicotine dependence was significantly higher in males compared with females (19.9\% and $7.1 \%, p<0.01)$. Jing Po men and women had the highest prevalence of current smokers $(72.2 \%$ vs $23.1 \%, p<0.01)$, whereas the highest prevalence of nicotine dependence was found in male Dai current smokers and female Li Shu current smokers (44.8\% vs $32.5 \%, p<0.01)$. Filtered cigarettes were the most popular form of tobacco used across all five ethnic groups. Over $75 \%$ of tobacco users initiated smoking and regularly smoked during adolescence, and those of minority ethnicity smoked regularly at a younger age than those of Han descent $(p<0.05)$. Individuals in all five ethnic groups with higher levels of education had a lower probability of current smoking status $(p<0.05)$, whereas a negative association of level of education with nicotine dependence was only observed in current smokers in the Han majority and Dai ethnic minority groups. Among Han majority current smokers, higher annual household income was associated with a higher risk of nicotine dependence $(p<0.05)$.

Conclusion Future interventions to control tobacco use should be tailored to address ethnicity and socioeconomic factors.

\section{INTRODUCTION}

Smoking remains a major public health problem worldwide. The WHO reported there are $>1.1$ billion smokers globally, and
Strengths and limitations of this study

- This present research is the first study to examine ethnic disparities in prevalence and patterns of smoking in the southwest Chinese population.

- Our large sample size enhances the validity of our results.

- High response rate (93.7\%) in this study.

- Prevalence of smoking was based on self-reporting, and may therefore be subject to recall bias.

projects $>1$ billion tobacco-related deaths this century. ${ }^{1}$ Non-communicable diseases (NCDs) cause $\sim 40$ million deaths each year, and many NCDs have tobacco-related causes and/or contributing factors. ${ }^{2}{ }^{3}$ Given these grave health hazards, WHO ranks tobacco smoking as a top 10 threat to human health for the 21st century.

Smoking behaviours were gendered from the outset: nearly all smokers were male at the beginning of 20th century. However, alongside economic and social development, the prevalence of female smokers increased in many countries. ${ }^{45}$ Moreover, the age at which people begin smoking has dropped lower over the last century in Asian countries like China. ${ }^{6}$ According to a previous study, smoking can lead to a $15.2 \%$ loss of health life years for females and $25.5 \%$ loss for males. ${ }^{7}$

As the world's largest tobacco producer and consumer, China accounts for about $28 \%$ of smokers globally. ${ }^{8}$ According to China Statistic Yearly 2014, China produces 2560.4billion cigarettes per year, with smokers numbering $>300$ million. In China, the death rate attributable to smoking was $16.5 \%$ in men and $1.7 \%$ in women in $2012 .{ }^{9}$

China is a multiethnic nation, home to 56 ethnic groups, each with unique customs. The largest ethnic group is Han, accounting for $92 \%$ of the total population. Many studies have explored racial and ethnic disparities in 
prevalence of smoking worldwide. ${ }^{10-12}$ In China, several studies have examined ethnic differences in prevalence of smoking and nicotine dependence ${ }^{13}{ }^{14}$ but the literature is sparse, especially with regard to ethnic minority communities in rural regions. Improved understanding of ethnic disparities in smoking and nicotine dependence is critical to effectively reducing and controlling its prevalence in China.

Yunnan Province stretches along China's southwestern border and is a major tobacco plantation region. Indeed, tobacco production is one of the largest industries in Yunnan, with 105 counties currently cultivating tobacco. Consequently, residents have higher tobacco exposure than the national level. ${ }^{15}$ Yunnan also has China's largest concentration of ethnic minorities, with 25 ethnic minority groups residing in the province, 15 of which only live in Yunnan. Traditions, heritage, culture, and lifestyles differ among these ethnic groups. Most of the ethnic minority population in Yunnan lives in rural or mountainous regions, lacks awareness of the harms of tobacco relative to the rest of the population, and as a result may have a higher smoking rate. However, little information is available on the prevalence and patterns of smoking and nicotine dependence among minorities in China, and the causes of those variations by ethnicity that are currently known are not well understood. Therefore, this study aimed to investigate ethnic disparities in prevalence and patterns of smoking and nicotine dependence among the Han majority and four unique ethnic minority groups ( $\mathrm{Na} \mathrm{Xi,} \mathrm{Li} \mathrm{Shu,} \mathrm{Dai} \mathrm{and} \mathrm{Jing} \mathrm{Po)} \mathrm{in} \mathrm{rural}$ southwest China.

\section{METHODS}

\section{Study area and population}

The study population consisted of residents of Yunnan Province, China who responded to the Yunnan Provincial Community Health Survey (YCHS) from 2015 to 2017, a survey supported by the National Natural Science Foundation of China. This survey was conducted in one Han majority county and four distinct ethnic minority-populated regions of Yunnan Province using a stratified multistage sampling technique. In stage 1, all 129 counties were divided into four strata (valley area, dam area, semi-mountain area and alpine area) based on the geographical characteristics of the regions. One Han majority county was randomly chosen from valley area, and one unique ethnic minority autonomous county was randomly chosen from each stratum, for a total of five counties. In stage 2, each selected county was further divided into three categories-economically advantaged, economically average and economically disadvantagedbased on wealth distribution (per capita gross domestic product). One township was then randomly selected from each of these three chosen groups, for a total of 15 townships. In stage 3 , three villages were chosen by probability proportional to size from each of the 15 townships. In the final stage, simple random sampling was conducted to select individuals aged $\geq 35$ years from each chosen village. The YCHS initially selected 7500 individuals aged $\geq 35$ years to participate, of which 7027 consented, representing an overall response rate of $93.7 \%$.

\section{Data collection and measurement}

Twenty medical students from Kunming Medical University were selected and trained as interviewers for data collection. Each participant who gave informed consent was interviewed in person by one of the interviewers using a pretested and structured questionnaire. Information on demographic characteristics, individual socioeconomic status including ethnicity, household income and level of education, and self-reported smoking habits was obtained through the questionnaire.

\section{Definitions}

Participants who reported that they had smoked $>100$ cigarettes in their life thus far as well as currently smoked any kind of tobacco product on a daily basis were categorised as current smokers. Self-reported current smokers were assessed for nicotine dependence using six questions from the Fagerstrom Test for Nicotine Dependence (FTND) ${ }^{16}$ FTND has 5 grades and includes 6 questions, resulting in a total score from 0 to 10 . Dependence was defined as a score $\geq 5$ in this study. Specifically, an FTND score from 0 to 2 was defined as very low dependence; a score from 3 to 4 was defined as low dependence; a score equal to 5 was defined as medium dependence; a score from 6 to 7 was defined as high dependence; and a score from 8 to 10 was defined as very high dependence. Annual household income was divided into three categories: low $(<\mathrm{US} \$ 450)$, medium (US\$450-800) and high (>US\$800). Level of education was also classified into three categories: illiterate, primary (grade 1-6) and middle (grade 7-9) or higher.

\section{Statistical analysis}

Data were double entered into an EpiData Entry V.3.1 electronic database and analysed using R V.3.2.0 software. Descriptive analysis techniques and $\chi^{2}$ tests were used in this study. Counts and percentages were used to present categorical variables.

The age-standardised prevalence of current smokers and nicotine dependence were computed by directly standardising to the overall sample. All statistical significance decisions were based on a two-tailed $p$ value of $<0.05$.

\section{RESULTS}

Table 1 shows the demographic characteristics of the participants. Participants in the study included 3434 (48.9\%) males and 3593 (51.1\%) females. Among the study participants, the percentage of male Han ethnic majority, $\mathrm{Na} \mathrm{Xi,} \mathrm{Li} \mathrm{Shu,} \mathrm{Dai} \mathrm{and} \mathrm{Jing} \mathrm{Po} \mathrm{ethnic} \mathrm{minori-}$ ties was $50.6 \%, 45.9 \%, 49.4 \%, 49.1 \%$ and $49.2 \%$, respectively. Han majority participants had the highest level of education and annual household income of the ethnic 
Table 1 Demographic characteristics of the study population

\begin{tabular}{|c|c|c|c|c|c|c|}
\hline & $\begin{array}{l}\text { Han ethnic } \\
\text { majority }\end{array}$ & $\begin{array}{l}\text { Na Xi ethnic } \\
\text { minority }\end{array}$ & $\begin{array}{l}\text { Li Shu ethnic } \\
\text { minority }\end{array}$ & $\begin{array}{l}\text { Dai ethnic } \\
\text { minority }\end{array}$ & $\begin{array}{l}\text { Jing Po } \\
\text { ethnic } \\
\text { minority }\end{array}$ & All \\
\hline Characteristics & n (\%) & $\mathrm{n}(\%)$ & n (\%) & n (\%) & n (\%) & n (\%) \\
\hline \multicolumn{7}{|l|}{ Sex } \\
\hline Male & 757 (50.6) & $644(45.9)$ & 675 (49.4) & 686 (49.1) & 672 (49.2) & $3434(48.9)$ \\
\hline Female & $738(49.4)$ & $758(54.1)$ & $691(50.6)$ & $711(50.9)$ & $695(50.8)$ & $3593(51.1)$ \\
\hline \multicolumn{7}{|l|}{ Age (years) } \\
\hline $35-44$ & $311(20.8)^{\star}$ & 405 (28.9) & 545 (39.9) & $336(24.1)$ & 467 (34.2) & 2064 (29.4) \\
\hline $45-59$ & $604(40.4)$ & 535 (38.2) & $538(39.4)$ & 575 (41.2) & 586 (42.9) & $2828(40.4)$ \\
\hline$\geq 60$ & $580(38.8)$ & $462(33.0)$ & $283(20.7)$ & $486(34.8)$ & $314(23.0)$ & 2125 (30.2) \\
\hline \multicolumn{7}{|l|}{ Level of education } \\
\hline Illiterate & $171(11.4)^{\star *}$ & $194(13.8)$ & $559(40.9)$ & 549 (39.3) & $406(29.7)$ & $1879(26.7)$ \\
\hline Primary (grade 1-6) & $730(48.8)$ & 648 (46.2) & $654(47.9)$ & $723(51.8)$ & $693(50.7)$ & $3448(49.1)$ \\
\hline Middle (grade 7-9) or higher & $594(39.7)$ & $560(39.9)$ & $153(11.2)$ & $125(8.9)$ & 268 (19.6) & $1700(24.2)$ \\
\hline \multicolumn{7}{|c|}{$\begin{array}{l}\text { Level of annual household income } \\
\text { (US\$) }\end{array}$} \\
\hline Low & $141(9.4)^{\star \star}$ & $147(10.5)$ & $693(50.7)$ & $637(45.6)$ & $608(44.5)$ & $2226(31.7)$ \\
\hline Medium & 467 (31.2) & 695 (49.6) & $524(38.4)$ & 646 (46.2) & 645 (47.2) & $2977(42.4)$ \\
\hline High & 887 (59.3) & $560(39.9)$ & 149 (10.9) & 114 (8.2) & 114 (8.3) & $1824(26.0)$ \\
\hline
\end{tabular}

${ }^{*} \mathrm{P}<0.05,{ }^{* *} \mathrm{p}<0.01$.

\begin{tabular}{|c|c|c|c|c|c|c|}
\hline Characteristics & $\begin{array}{l}\text { Han ethnic } \\
\text { majority }\end{array}$ & $\begin{array}{l}\text { Na Xi ethnic } \\
\text { minority }\end{array}$ & $\begin{array}{l}\text { Li Shu ethnic } \\
\text { minority }\end{array}$ & $\begin{array}{l}\text { Dai ethnic } \\
\text { minority }\end{array}$ & $\begin{array}{l}\text { Jing Po } \\
\text { ethnic } \\
\text { minority }\end{array}$ & All \\
\hline \multicolumn{7}{|l|}{ Sex } \\
\hline Male & $59.2^{\star \star}$ & $67.1^{\star \star}$ & $59.6^{\star \star}$ & $66.9^{\star \star}$ & $72.2^{\star \star}$ & $64.8^{\star \star}$ \\
\hline Female & 1.1 & 0.8 & 11.3 & 0.7 & $23.1^{* *}$ & 7.1 \\
\hline \multicolumn{7}{|l|}{ Age (years) } \\
\hline $35-44$ & $36.5^{\star}$ & $34.9^{*}$ & $32.1^{*}$ & $38.5^{\star}$ & $41.3^{*}$ & $36.2^{*}$ \\
\hline $45-59$ & 34.3 & 31.5 & 35.1 & 35.1 & 49.5 & 35.3 \\
\hline$\geq 60$ & 23.1 & 27.2 & 39.2 & 26.9 & 52.2 & 31.0 \\
\hline \multicolumn{7}{|l|}{ Level of education } \\
\hline Illiterate & $38.7^{\star \star}$ & $35.8^{*}$ & $36.1^{*}$ & $35.2^{*}$ & $49.6^{*}$ & $39.5^{*}$ \\
\hline Primary (grade 1-6) & 31.0 & 32.5 & 34.2 & 31.3 & 45.9 & 35.3 \\
\hline Middle (grade 7-9) or higher & 26.8 & 28.7 & 31.4 & 31.7 & 40.2 & 30.6 \\
\hline \multicolumn{7}{|l|}{ Level of annual household income } \\
\hline Low & 24.2 & 27.2 & 35.6 & 37.4 & 46.4 & 33.8 \\
\hline Medium & 28.7 & 33.5 & 33.8 & 36.7 & 48.7 & 36.2 \\
\hline High & 28.1 & 29.1 & 34.2 & 33.8 & 43.2 & 34.4 \\
\hline All & 30.2 & 31.3 & 35.1 & 33.2 & $47.4^{*}$ & 35.1 \\
\hline
\end{tabular}

${ }^{*} \mathrm{P}<0.05$, ${ }^{* *} \mathrm{P}<0.01$, the $\chi^{2}$ tests for independence were conducted for prevalence of current smoking across socioeconomic status in all five studied ethnicities. 
Table 3 Age-standardised prevalence of nicotine dependence among current smokers by socioeconomic status (\%)

\begin{tabular}{|c|c|c|c|c|c|c|}
\hline Characteristics & $\begin{array}{l}\text { Han ethnic } \\
\text { majority }\end{array}$ & $\begin{array}{l}\mathrm{Na} \mathrm{Xi} \text { ethnic } \\
\text { minority }\end{array}$ & $\begin{array}{l}\text { Li Shu ethnic } \\
\text { minority }\end{array}$ & $\begin{array}{l}\text { Dai ethnic } \\
\text { minority }\end{array}$ & $\begin{array}{l}\text { Jing Po } \\
\text { ethnic } \\
\text { minority }\end{array}$ & All \\
\hline \multicolumn{7}{|l|}{ Sex } \\
\hline Male & $42.7^{\star \star}$ & $44.8^{\star *}$ & $38.9^{*}$ & $42.6^{\star \star}$ & $44.4^{\star \star}$ & $42.8^{\star \star}$ \\
\hline Female & 0.0 & 0.0 & $32.5^{\star *}$ & 0.0 & 19.9 & 22.1 \\
\hline \multicolumn{7}{|l|}{ Age (years) } \\
\hline $45-59$ & 37.3 & 42.5 & 42.3 & 45.8 & 38.5 & 41.0 \\
\hline$\geq 60$ & 44.7 & 45.3 & 36.9 & 43.1 & 35.0 & 40.8 \\
\hline \multicolumn{7}{|l|}{ Level of education } \\
\hline Illiterate & $48.0^{*}$ & $45.0^{*}$ & $39.7^{*}$ & $50.4^{*}$ & $36.5^{\star}$ & $41.9^{*}$ \\
\hline Low & 34.2 & 43.2 & 35.1 & 37.7 & 38.3 & 40.0 \\
\hline Medium & 35.6 & 42.8 & 42.2 & 36.2 & 36.0 & 39.2 \\
\hline High & $44.5^{*}$ & 42.7 & 37.6 & 37.4 & 37.6 & 42.8 \\
\hline All & 42.0 & 44.0 & 37.9 & 42.1 & 38. & 40.6 \\
\hline
\end{tabular}

${ }^{\star} \mathrm{P}<0.05$, ${ }^{\star *} \mathrm{p}<0.01$, the $\chi^{2}$ tests for independence were conducted for prevalence of nicotine dependence across socioeconomic status in all five studied ethnicities.

minorities studied, whereas those of the Li Shu ethnic minority had the lowest level of education and those of the Dai ethnic minority had the lowest annual household income level of the five ethnicities studied $(p<0.01)$.

As shown in tables 2 and 3, the overall prevalence rate of current smoking was $35.1 \%$, and the rate of nicotine dependence among current smokers was $40.6 \%$. Males had a significantly higher prevalence of current smoking than females $(64.8 \%$ and $44.4 \%, \mathrm{p}<0.01)$ in all five studied ethnicities. Moreover, with the exception of $\mathrm{Li}$ Shu and Jing Po ethnic minority groups (where smoking prevalence among females is substantial, with 11.3\% and $23.1 \%$, respectively), prevalence of current smoking was consistently high among males, and consistently nearly zero among females. The prevalence of nicotine dependence was much higher in male current smokers than female current smokers $(7.1 \%$ and $19.9 \%, \mathrm{p}<0.01)$. Among the five populations studied, males of the Jing Po ethnicity had the highest prevalence of current smoking, whereas male current smokers of $\mathrm{Na} \mathrm{Xi}$ descent had the highest prevalence of nicotine dependence $(\mathrm{p}<0.01)$. Females in the Jing Po ethnic minority group also had the highest prevalence rate of current smoking $(p<0.01)$. Participants aged 35-44 years in the Han, Na Xi and Dai ethnicities had the highest prevalence of current smokers $(p<0.05)$. Education was inversely correlated with probability of smoking in all five ethnicities studied: those with higher levels of education had a lower likelihood of currently smoking $(p<0.05)$. Among Han and Dai current smokers, participants with higher levels of education also had a lower probability of nicotine dependence. Among
Han current smokers, higher annual household income was associated with a higher risk of nicotine dependence $(\mathrm{p}<0.05)$.

Table 4 indicates patterns of smoking among current smokers in rural Yunnan Province. Filtered cigarettes were the most popular form of tobacco used among all five ethnicities studied $(p<0.01)$, particularly in the $\mathrm{Na} \mathrm{Xi}$ ethnic minority $(98.4 \%)$. The second most used form of tobacco varied by ethnicity: hookah/water pipe in Han $(18.2 \%)$ and $\mathrm{Na} \mathrm{Xi}$ populations $(0.7 \%)$, pipe tobacco among Dai (12.7\%) and Li Shu (5.3\%) ethnic minorities, and chewing tobacco in the Jing Po population (27.9\%). The Jing Po ethnic minority had the lowest age of smoking initiation, but the age of smoking initiation and of regular smoking for all five ethnicities studied was 12-20 years $(\mathrm{p}<0.01)$. Na Xi, Li Shu and Dai ethnic minorities had a younger average age of regular smoking than the Han population $(\mathrm{p}<0.05)$. More than $85 \%$ of smokers in the study smoked in public places (defined as having smoked in a public place in the prior 7 days); the Han population had the highest rate of smoking in public places $(\mathrm{p}<0.05)$.

\section{DISCUSSION}

The findings indicate a high prevalence rate of smoking and nicotine dependence in rural southwest China, particularly among male adults of ethnic minority descent. Further, the data reveal significant ethnic differences in prevalence and patterns of smoking: both current smoking and nicotine dependence vary by ethnic minority group. 
Table 4 Patterns of smoking among current smokers in rural regions of Yunnan Province, China (\%)

\begin{tabular}{|c|c|c|c|c|c|c|}
\hline Variables & $\begin{array}{l}\text { Han ethnic } \\
\text { majority }\end{array}$ & $\begin{array}{l}\text { Na Xi ethnic } \\
\text { minority }\end{array}$ & $\begin{array}{l}\text { Li Shu } \\
\text { ethnic } \\
\text { minority }\end{array}$ & $\begin{array}{l}\text { Dai ethnic } \\
\text { minority }\end{array}$ & $\begin{array}{l}\text { Jing Po } \\
\text { ethnic } \\
\text { minority }\end{array}$ & All \\
\hline \multicolumn{7}{|c|}{ Use of various forms of tobacco } \\
\hline Filtered cigarettes & $69.2^{\star \star}$ & 98.4 & 86.7 & 93.3 & 60.8 & 80.0 \\
\hline Unfiltered cigarettes & 17.6 & 0.0 & 1.0 & 3.2 & 3.9 & 5.0 \\
\hline Hookah / water pipe & 18.2 & 0.7 & 2.1 & 0.2 & 0.8 & 4.1 \\
\hline Hand-rolled cigarettes & 2.2 & 0.4 & 5.0 & 12.7 & 13.3 & 7.3 \\
\hline Chewing tobacco & 0.0 & 0.0 & 0.0 & 0.2 & 27.9 & 7.3 \\
\hline \multicolumn{7}{|c|}{ Age of smoking initiation (years) } \\
\hline$\leq 11$ & 1.3 & 2.3 & 0.6 & 6.9 & $7.7^{\star \star}$ & 3.9 \\
\hline \multicolumn{7}{|c|}{ Age of regular smoking (years) } \\
\hline$\leq 11$ & $0.3^{\star}$ & 1.0 & 0.4 & 4.3 & 5.0 & 2.3 \\
\hline $12-20$ & 66.8 & 75.2 & 79.0 & 68.7 & 56.9 & 68.4 \\
\hline $21-34$ & 31.0 & 21.5 & 18.0 & 23.8 & 29.4 & 25.3 \\
\hline$\geq 35$ & 1.9 & 2.3 & 2.6 & 3.3 & 8.7 & 4.0 \\
\hline
\end{tabular}

Location of smoking in the previous

7 days

\begin{tabular}{lllllll} 
Home & $13.2^{*}$ & 11.3 & 9.2 & 11.2 & 10.9 & 10.9 \\
Public spaces (schools, hospitals and & 86.8 & 88.7 & 91.8 & 88.8 & 89.1 & 89.1 \\
so on) & & & & & \\
\hline
\end{tabular}

${ }^{*} \mathrm{P}<0.05,{ }^{* *} \mathrm{p}<0.01$, the $\chi^{2}$ tests for independence were conducted for each pattern of smoking across the ethnic groups.

The present study also found that filtered cigarettes were the most popular tobacco form in all five studied ethnicities in rural southwest China. This aligns with previous Chinese studies. ${ }^{15}{ }^{17}$ Furthermore, the finding that the second most common tobacco form among the Han population was hookah/water pipes is also consistent with previous research. ${ }^{15}$ Chewing tobacco was particularly popular in the Jing Po ethnic minority. This is possibly due to the fact that the majority of the Jing Po minority lives in semi-mountainous and mountainous areas where tobacco with a stronger taste and higher tar content is preferred. These ethnic differences indicate culture plays a role in shaping smoking behaviours.

The present study also revealed that most current smokers in the five studied ethnic groups initiate smoking as well as begin regular smoking during adolescence, a finding which accords with previous studies ${ }^{18}{ }^{19}$ indicating smoking is a serious problem for teenagers in rural southwest China. In addition, all four ethnic minorities studied had a lower age of smoking initiation and of regular smoking than the Han population. In particular, the Jing Po ethnic minority had the highest proportion of initiation of smoking and regular smoking behaviours at $<11$ years of age. These findings thus underscore an urgent need for governmental interventions to improve health education and to increase efforts to prevent adolescents from smoking initiation, especially in ethnic minority areas.

In the present study, over $86 \%$ of current smokers in the five studied ethnic groups smoked in public places over the 7 days prior to the collection of data, a significantly higher rate than observed in a prior Chinese study $(63.3 \%)$ as well as studies from other Asian nations, including India (29.9\%), the Philippines (32.6\%) and Thailand $(27.2 \%),{ }^{20}$ indicating public places have become more crowded with smoking in rural southwest China. The findings suggest it is essential to raise awareness of the harms of smoking and to implement comprehensive smoke-free policies to reduce levels of exposure to secondhand smoke in public places.

In the present study, males had a markedly higher prevalence rate of current smoking and nicotine dependence than females among all five ethnicities studied, while prevalence of current smoking in males in all four studied ethnic minorities was higher than in the Han population. That males smoked significantly more and were more likely to have a nicotine addiction than females accords with other studies. ${ }^{21} 22$ However, 
the overall prevalence rate of current smoking and nicotine dependence among males was higher in the present study than in both previous Chinese studies as well as studies in other countries. ${ }^{1823}$ The findings thus provide further evidence that smoking and nicotine dependence remains a widespread challenge for rural Chinese male adults, particularly in ethnic minority populations.

Our finding that individuals with a lower educational level had a higher prevalence of current smoking and nicotine dependence in all five studied ethnicities accords with other studies of the relationship between education and tobacco use. ${ }^{21} 24$ Namely, while those with high levels of education tend to have healthier lifestyles, those with low levels of education are more likely to believe false information about tobacco, lack awareness about tobacco hazards, and pay insufficient attention to the harm of tobacco and their own health conditions, leading to a comparatively high level of smoking and nicotine dependence. ${ }^{24}$ However, our study indicated that the differences in prevalence of current smoking by education are modest (only 5\%-10\% differences). This result differs from previous studies where large differences in prevalence of current smoking by education were observed (over $20 \%$ differences) ${ }^{25}{ }^{26}$ The reasons behind this inconsistent effect of education on current smoking levels require further research.

In the present study, whereas individual annual income had no association with current smoking among the five studied ethnic groups, it was positively correlated with nicotine dependence in the Han majority population. This result is consistent with previous Chinese studies, ${ }^{15}$ but differs from some western studies' findings that those with lower incomes had a higher probability of nicotine dependence. ${ }^{27}$ The reason for this dichotomy is unclear, and further investigation is needed to examine the exact nature of the association between income and nicotine dependence.

The findings of the present study may be limited. Prevalence of smoking was based on self-reporting and was not validated with biochemical tests. It may therefore be subject to recall bias, leading to an underestimated prevalence of smoking in the study population.

\section{CONCLUSION}

This study reveals ethnic differences in prevalence and patterns of smoking and nicotine dependence in rural southwest China. The results of our study underscore the necessity of considering ethnicity as a factor in future tobacco control programme, and highlight the need for future tobacco cessation interventions to target men and those with lower education levels.

Contributors CL conceptualised the research idea and revised the manuscript. X-MW and CW carried out the study and drafted the manuscript with the same contributions. ARG worked on the manuscript.

Funding This study was supported by grants from the National Natural Science Foundation of China (Grant number: 71663035, 71263032), Major Union Specific
Project Foundation of Yunnan Provincial Science and Technology Department, and Kunming Medical University (2017FE467(-002)), Programme for Innovative Research Team (in Science and Technology) in University of Yunnan Province ((2018)134) and Science and Technology Innovation Team Foundation of Kunming Medical University (CXTD201706).

Competing interests None declared.

Patient consent for publication Not required.

Ethics approval This study was approved by the Ethics Committee of Kunming Medical University. Oral informed consent was obtained from all persons participating in the study.

Provenance and peer review Not commissioned; externally peer reviewed.

Data availability statement Data are available upon reasonable request.

Open access This is an open access article distributed in accordance with the Creative Commons Attribution Non Commercial (CC BY-NC 4.0) license, which permits others to distribute, remix, adapt, build upon this work non-commercially, and license their derivative works on different terms, provided the original work is properly cited, appropriate credit is given, any changes made indicated, and the use is non-commercial. See: http://creativecommons.org/licenses/by-nc/4.0/.

\section{REFERENCES}

1. World Health Organization. Who report on the global tobacco epidemic, 2008: the MPOWER package Geneva. Switzerland: WHO Press, 2008.

2. Organization $\mathrm{W} \mathrm{H}$. Who report on the global tobacco epidemic, 2017: monitoring tobacco use and prevention policies, 2013.

3. Nash SH, Liao LM, Harris TB, et al. Cigarette smoking and mortality in adults aged 70 years and older: results from the NIH-AARP cohort. Am J Prev Med 2017;52:276-83.

4. Mandil A, BinSaeed A, Ahmad S, et al. Smoking among university students: a gender analysis. J Infect Public Health 2010;3:179-87.

5. Tiwari RV, Gupta A, Agrawal A, et al. Women and tobacco use: discrepancy in the knowledge, belief and behavior towards tobacco consumption among urban and rural women in Chhattisgarh, central India. Asian Pac J Cancer Prev 2015;16:6365-73.

6. China Centre for Disease Control and Prevention. Main results of 2010 national disease surveillance areas (DSPs) monitoring of chronic diseases and risk factors, 2011. Available: http://www. chinacdc.cn/zxdt/201109/t20110906_52141.htm

7. Tombor I, Paksi B, Urbán R, et al. Epidemiology of smoking in the Hungarian population, based on national representative data. Clin Exp Med J 2011;5:27-37.

8. Méndez D, Alshanqeety $\mathrm{O}$, Warner KE. The potential impact of smoking control policies on future global smoking trends. Tob Control 2013;22:46-51.

9. Li S, Meng L, Chiolero A, et al. Trends in smoking prevalence and attributable mortality in China, 1991-2011. Prev Med 2016;93:82-7.

10. Sakuma K-LK, Felicitas-Perkins JQ, Blanco L, et al. Tobacco use disparities by racial/ethnic groups: California compared to the United States. Prev Med 2016;91:224-32.

11. El-Toukhy S, Sabado M, Choi K. Trends in susceptibility to smoking by race and ethnicity. Pediatrics 2016;138:e20161254.

12. Soulakova JN, Huang H, Crockett LJ. Racial/Ethnic disparities in consistent reporting of smoking-related behaviors. J Addict Behav Ther Rehabil 2015;04.

13. Geng XW, Yang JJ, XG L. Comparative study on smoking status between college students in Tibetan ethnic minority and Han majority. Chin J Sch Health 2011;32:705-6.

14. Cheng WR, Cai L, Cui WL, et al. Comparative study of differences in prevalence of tobacco exposure between ethnic minorities in Tong HAl County in Yunnan Province. Modern Preventive Medicine 2015;42:489-91.

15. Cai L, Wu X, Goyal A, et al. Patterns and socioeconomic influences of tobacco exposure in tobacco cultivating rural areas of Yunnan Province, China. BMC Public Health 2012;12:842.

16. Heatherton TF, Kozlowski LT, Frecker RC, et al. The Fagerstrom test for nicotine dependence: a revision of the Fagerstrom tolerance questionnaire. Addiction 1991;86:1119-27.

17. Yang T, Li F, Yang X, et al. Smoking patterns and sociodemographic factors associated with tobacco use among Chinese rural male residents: a descriptive analysis. BMC Public Health 2008;8:248.

18. Ma Y, Wen L, Cui W, et al. Prevalence of cigarette smoking and nicotine dependence in men and women residing in two provinces in China. Front Psychiatry 2017;8. 
19. Pedro JM, Brito M, Barros $\mathrm{H}$. Tobacco consumption and nicotine dependence in Bengo Province, Angola: a community-based survey. PLoS One 2017;12:e0188586.

20. Bush J, White M, Kai J. Understanding influences on smoking in Bangladeshi and Pakistani adults: community based, qualitative study. BMJ 2003;326:962.

21. Coban FR, Kunst AE, Van Stralen MM, et al. Nicotine dependence among adolescents in the European Union: how many and who are affected? J Public Health 2018;26.

22. Mbulo L, Palipudi KM, Andes L, et al. Secondhand smoke exposure at home among one billion children in 21 countries: findings from the global adult tobacco survey (GATS). Tob Control 2016;25:e95-100.

23. Reitsma MB, Fullman $\mathrm{N}, \mathrm{Ng} \mathrm{M}$, et al. Smoking prevalence and attributable disease burden in 195 countries and territories, 1990-
2015: a systematic analysis from the global burden of disease study 2015. Lancet 2017;389:1885-906.

24. Chen GB, Zou XN, Chen YL, et al. Investigation of nicotine dependence and its influencing factors of smokers in China. Medicine and Society 2013;26:1-4.

25. Yaya S, Bishwajit G, Shah V, et al. Socioeconomic disparities in smoking behavior and early smoking initiation among men in Malawi. Tob Use Insights 2017;10.

26. Hiscock R, Bauld L, Amos A, et al. Socioeconomic status and smoking: a review. Ann N Y Acad Sci 2012;1248:107-23.

27. Hobkirk AL, Krebs NM, Muscat JE. Income as a moderator of psychological stress and nicotine dependence among adult smokers. Addict Behav 2018;84:215-23. 